caused by the caloric evolved by the transition of the aqueous vapour of the breath into the liquid or solid form.

Before seeing Dr. Roberts's explanation I referred the matter to the greatest living authority on heat, and he, after carefully repeating my experiments, was of opinion that the heat was produced by the compression of the air when forced through the material. Had he known of Dr. Roberts's simple but ingenious variation of the experiment there is no doubt he would have accepted Dr. Roberts's explanation.

R. E. DUDGEON

November 18

THE following experiment may serve to supplement the observations of Dr. Roberts as to the cause of the high reading of a thermometer wrapped in a handkerchief and placed in the mouth, An ordinary non-registering thermometer was wrapped in about twelve folds of a dry linen handkerchief placed in the mouth, and the following readings taken at intervals of one minute :Inspiration was effected through the nostrils, expiration through the handkerchief. The thermometer was in the mouth from the beginning to the end of the experiment. Temperature under the tongue before commencing, $37^{\circ} \circ \mathrm{OC}$. The reading of the thermometer wrapped as above described, one minute after introduction into the mouth, was $43^{\circ} \circ$. At the end of the second minute, $44^{\circ} \cdot \mathrm{r}, 3^{\text {rd }} 42^{\circ} \cdot 9$, 4 th $41^{\circ} \cdot 2$, 5 th $39^{\circ} \cdot 6$, 6th $3^{\circ} \cdot 2$, 7 th $37^{\circ} \cdot 1,8$ th $36^{\circ} \cdot 9$, 9th $36^{\circ} \cdot 9$, \&c. After the experiment the temperature under the tongue was $37^{\circ} \cdot 6$. Capillarity is probably the chief cause of the rapid condensation of water, and the consequent liberation of heat in the dry fabric.

In connection with the above I may mention a schoolboy's trick, viz., gripping the arm of a schoolfellow with the teeth and breathing forcibly through his coat-sleeve. The sensation of heat thus produced is much greater than when the breath is allowed to impinge on the bare skin.

In conclusion, I must freely confess that Dr. Dudgeon completely upset my objection, as to compression of the bulb having anything to do with the high reading, by the experiments quoted in his last letter. F. J. M. P.

\section{Coral Reefs and Islands}

IN my letter on "Coral Reefs and Islands," published in NATURE, vol. xxii. p. 558, I have just noticed an important slip in writing which demands correction.

In the third paragraph and ninth line, for metres read miles, so that the passage shall read thus: "On the Florida coast we have barriers with channels 10-40 miles wide."

More accurately, the space between the southern coast of Florida and the line of Keys (old barrier reef) gradually widens from a few miles in its eastern to more than 40 miles in its western part. The channel between the line of Keys and the present reef is $6-7$ miles wide and about $\times 50$ miles long.

Berkeley, California, November 2 JOSEPH LECONTE

\section{Vox Angelica}

I IIAVE received a letter from Mr. Samuel Ray of Stoke Newington with reference to my remarks on the Vox Angelica stop on an Estey American organ. Mr. Ray informs me that Gordon's supplementary tuning-valve is used for the desired effects. The rationale of the method is, that by partly closing the mute the reeds are flattened, just as one reed is when the key is partially depressed. $\mathrm{Mr}$. Ray also says, that by pulling out the stop a little way and making the reeds beat the latter are liable to be drawn out of tune; but this was the original method, but is now improved upon. A separate mute is placed on the top of the tules, so that the wind strikes one of the sets of reeds vertically, whereby undue strain is avoided.

Woodville House, Rugby, November I 8

GeORge RAYLEigh Vicars

\section{Fascination (?)}

PROBAlLy none of your readers have thought it worth while to make any comment on the letters on this subject which have recently appeared, because it would seem needless to discuss the origin of "fascination" by means of the eye of a snake (or whatever may be the stimulus to the alleged condition) while all the evidence we can obtain from these reptiles in confinement proves that the condition does not exist. It devolves upon those who might object to observations on reptiles in a glass case as untrustworthy, to show us why-all their other actions being normal-the prisoners should not exhibit the same habit in respect to this "fascination," as they are alleged to practise when free. It is rather late in the year now; but if Mr. L. P. Gratacap will take the first opportunity of seeing snakes feed, and if any of your readers will pay a visit to the Zoological Gardens, both he and they will, I think, come to the conclusion that, beyond the expression of a little surprise (on the part of ducks and pigeons chiefly) which soon wears off at the sight of an unfamiliar object, both the birds and animals regard the snakes with marked unconcern. I have seen a guinea-pig, after finding no place of exit from the cage, quietly settle itself down in the midst of the coils of an Australian constrictor, shat its eyes and go to sleep. Ten minutes afterwards the snake Fiad moved, and the guinea-pig was washing its face with its paws. Not once, but a dozen times, a rabbit has nibbled the nose of a River Jack viper ( $V$. rhinoceros) in a pretty, inquiring way, heedless of the strong blows the reptile would administer with its snout to the impertinent investigator of that queerlooking object. For fully ten minutes one day a rabbit sat gazing at the poised and threatening head of a puff adder, now and then reaching forward to smell the reptile's nose, and anon sitting on its hind legs to wash its ears, and again returning to the "fascinating" object of its inquiries. If during that time the rabbit had fallen into the state of trance, it was so soon released from that condition as to be able to attend to its own comfort and busy itself about its toilet. The birds show no more recognition than the other animals of the dangerous position in which they are placed. We see them hopping about on the snakes and pecking lustily at their scales; sitting on the branches, preening their feathers and behaving themselves just as though no such dreadful (or pleasing?) sensation as "fascination" was possible!

I saw once a sparrow perched upon the body of a snake twisted round a branch, and preening itself. By-and-by a constrictor crept up slowly, touched the bird with its nose, and then threw the crushing folds around it. The deliberate approach of the snake and the unconscious attitude of the sparrow, concerned about its private affairs, would have staggered any oxdinary believer in "fascination." I have closely watched the behaviour of snakes intent on feeding. It may be a sudden rush, when the victim has no time to see its enemy, or the gradual, lazy advance of the reptile; in cither case the doomed victim betrays no suspicion of danger-at least so far as I have been able to ascertain after passing some hundreds of hours contemplating the snakes in the unequalled representative collection of the Zoological Society.

The expression in Mr. Gratacap's letter, "glittering" eyes, applied to the orbits of a snake, which are veiled by the "antocular" membrane, and capable of very slight movement, may remind us of Virgil's "Suffecti sanguine et igni," and help to confirm the "basilisk" (not a snake, by-the-by) superstition, but can only serve to perpetuate a myth. Whatever may be the value of Mr. Foot's opinion, I would ask, "Who has ever seen a snake "raise its tail" after the manner of the cats?"

Charles Darwin has much to say on this subject to any one who chooses to consult the "Origin of Species." He does not see any advantage in the cat's "waving" tail or the noise of the "rattle" of Crotalus, for no predatory animal would derive any benefit from a signal of warning to its prey. The snake certainly never "waves" its tail when intent on mischief.

\section{ARTHUR NICOLS}

\section{Soaring of Birds}

REFERRING to NATURE, vol. xxiii. p. Io, may I suggest the following?-The question seems to be: "How can birds, having attained a certain elevation, thence rise without further miscular effort?"! If I am not in error in what follows, they can theoretically do so if they start with a difference between their horizontal velocity and that of the wind, and end with a less difference; e.g., if they start at rest with respect to the earth, and end by drifting with the wind entirely.

Take this last case, and consider the earth as plane, and the wind as horizontal, and having a velocity $=v$ with respect to the [earth and] bird. Finally we suppose the bird gains a horizontal momentum $=m v$. Then, by conservation of horizontal momentun, the only force :cting being vertical, the air must lose an equal horizontal momentum.

Now we know that in all cases of bodies colliding and ultimateiy acquiring the same velocity, while we have conservation 